\title{
FIRE SIMULATION IN A FULL-SCALE BILEVEL RAIL CAR: EXPERIMENTAL ANALYSIS TO ASSESS PASSENGER SAFETY
}

\author{
E. TRULLI ${ }^{1}$, E.C. RADA ${ }^{2,3}$, F. CONTI ${ }^{3}$, N. FERRONATO ${ }^{3}$, M. RABONI ${ }^{3}$, L. TALAMONA ${ }^{3}$ \& V. TORRETTA ${ }^{3}$ \\ ${ }^{1}$ School of Engineering, University of Basilicata, Italy. \\ ${ }^{2}$ Department of Civil, Environmental and Mechanical Engineering, University of Trento, Italy. \\ ${ }^{3}$ Department of Theoretical and Applied Sciences, University of Insubria, Italy.
}

\begin{abstract}
The increasingly occurrence of fires risk within public transport facilities prompted many countries to improve public vehicle security implementing specific researches. The provision of a useful reference point for the compatibility of passengers and goods rail transport, with final attention to the preservation of the environment and the human health, represent the general target of such investigations. As a result, this manuscript presents the outcomes of a full-scale experimentation of fire in a bilevel rail car for passengers' transport, useful to evaluate human exposure to toxic loads during a fire. The research consisted in the temperature measurement in various positions and its comparison with a simulation model based on the theoretical approach. Furthermore, visibility and air quality $\left(\mathrm{O}_{2}, \mathrm{CO}_{2}, \mathrm{CO}, \mathrm{TOC}\right.$, particulate matter) were analyzed inside the rail car. The comparison between numerical methods and data obtained allow understanding that the numerical model is an effective simulation tool of fire dynamics, especially within the lower deck, although it underestimates the trend of air temperature in the upper deck. Overall, the fire causes a rapid and considerable reduction of oxygen, down to a minimum value of $9.6 \%$ by volume, and an increase of particulate matter concentration and total organic carbon, up to maximum values of respectively $2200 \mathrm{mg} / \mathrm{Nm}^{3}$ and $800 \mathrm{mg} / \mathrm{Nm}^{3}$. Evaluations about the toxicological risk for human health and the environment are reported within the study, highlighting difficulties and threats in fire risk prediction and human exposure to toxic load as function of numerous factors, such as construction materials of railcars and passenger health state.

Keywords: environmental risk, fire, rail car fire, rail transport, safety risk.
\end{abstract}

\section{INTRODUCTION}

In the last years, many accidental fires occurred in passenger railcars, in most cases with serious consequences to human health and to the environment [1]. Fire is often associated with explosion, in case of freight rail cars. A recent Italian example is represented by the explosion that occurred in 2009 in Viareggio (Italy) due to a freight train loaded with GPL derailed at midnight through the station and triggers the apocalypse in the city center: a series of explosions and fire. This tragedy led to over 30 deaths and several dozens wounded as well as severe damage to buildings adjacent the station [2]. At the international level, many similar tragedies could be cited $[3,4]$.

The occurrence of such many accidents have prompted many countries to improve the public transport security, bringing to the development of specific researches. The general target is the improving of the overall transport security and the provision of a useful reference point for the social debate related to the compatibility of passengers and goods rail transport, with final attention to the preservation of the environment and the human health [5-7]. Through the project 'Trasfeu' of the European Commission [8], and specifically under the Seventh Framework Programme, relevant researches in this field were implemented. Train manufacturers, subcontracting companies, research laboratories and universities have taken actions in order to improve the level of safety associated with the transport $[9,10]$. 
The scientific literature lists many studies of fires in railway wagons. Many of these studies relate to countries' regulations to prevent fires, the study of materials and modeling experiences, with both theoretical and physical models. Despite that, rather scarce are the fire experimentation with full-scale rail cars $[11,12]$.

The research related to this publication was addressed to the following activities:

- actual measurements of physical and chemical parameters of combustion that takes place in a full-scale railway carriage for passenger transport;

- use of modeling simulations to describe with sufficient reliability fire spreading within railway carriage;

- detection of indoor air quality during the fire and evaluation of the consequences on the external environment.

These activities provide the basic information on which the risk analysis can be carried out. In this research the risk analysis is developed at an early stage.

The correct predictions, by means of a numerical model, of the fire dynamics can determine an important aid to design a railway carriage (for example, the choice of materials) and for the management of fire emergencies. Fire engineering is a reliable assessment tool capable to adher to the real boundary conditions, unlike the prescriptive regulatory scheme. The assessment approach to fire safety engineering has been formalized for the first time by an international standardization body in 1999, with the technical report ISO TR 13387-Fire Safety Engineering [13]. However, Fire Safety Engineering is a recent discipline only in part. The dissemination and study of theories that allow investigating the characteristics of a fire is a discipline that began to develop in the 70s. From that time to present there have been numerous experiments that allowed building current theories [14]. Nevertheless, a fire still remains a phenomenon only partially encoded. Indeed, the description of a railway carriage fire has a very high difficulty degree, and the consequences of such event can be very serious for several reasons: high temperatures, slightest chance of escape, and air contamination. For that reason, railways are classified by Directive 2006/90/EC as places of high risk in case of fire [15]. Besides this classification, the quantification of the railways risk provides the parameter that must be objectively studied and analysed to verify whether a given facility has an acceptable security level or not. Inside the railways, many factors are able to influence the risk level and the vulnerability of the transport system in case of accident (fire, explosion, etc.) [16]: electrification and signalling systems of the trains in movement; crowding of stations and trains; physical and geometrical characteristics of rail cars and technological preventing safety devices; systems and strategies for mitigating the effects of the fire, (e.g. automatic fire extinguishing systems, fume extraction, systems of partitioning, behaviour of materials to fire, etc.); factors external to the transport system, which can cause serious and unpredictable consequences (e.g. forest fires, traffic accidents, outside explosions, etc.).

The application modeling has served only to determine the magnitude order of the parameters describing the process. The use of other models might give different results, but this is not the object of the manuscript. Understand the magnitude order of the parameters is important also because any managerial/structural measures would use a safety coefficient greatly exceeding the outputs of the models. Another important aspect is that the results may change considerably depending on the interior materials which are different from train to train, and, very often, in the same train from carriage to carriage. So, the furniture in this case exposed is only indicative and is not representative of railway vehicles in circulation. These reasons make not applicable and useful a sensitivity analysis. 


\section{MATERIALS AND METHODS}

The fire simulation was carried out in an Italian railway station, on a bilevel passenger rail car of a typical regional train which travels full of workers and students during transport peak times. The rail car fire simulation was organized in collaboration with LS Fire Laboratory. The dimensions of the rail car are: carriage length: $=24.00 \mathrm{~m}$; carriage width $=2.84 \mathrm{~m}$; carriage height $=3.95 \mathrm{~m}$. The vehicle consists of: 39 windows; 4 external doors; 2 doors catwalk; 60 seats in the lower deck; 60 seats in the upper deck; 12 seats in the entrance area (atria). Table 1 shows the simulation parameters and the materials used.

The fire ignition was made by means of a burner powered by propane, positioned between two seats in the central part of the lower deck. The burner run with a power output of $150 \mathrm{~kW}$. During the fire simulation, within the rail car continuous measurement of temperature, visibility and indoor air quality were performed. Figure 1 shows the location of the burner (orange) and of the four control points (A and B in the lower deck; C and D in the upper deck) for temperature, visibility and air quality (for air quality only points B). The control points were positioned at head height (1.7 $\mathrm{m}$ above the floor). Fire testing of materials and components for trains was made according to EN 45545-2 that defines a classification system that specifies requirements for fire behavior of materials and products used in trains.

The rail car interior was equipped for a continuous temperature and visibility analysis. Temperature was detected with 56 thermocouples located in different points of the two

Table 1: Test conditions and main characteristics of the combustible materials.

\begin{tabular}{lll}
\hline & Parameter & Value \\
\hline $\begin{array}{l}\text { Test conditions } \\
\text { Duration of the simulation }(\mathrm{s})\end{array}$ & \\
Initial ambient temperature $\left({ }^{\circ} \mathrm{C}\right)$ & & $900[\mathrm{~s}]$ \\
Ambient pressure $(\mathrm{Pa})$ & & $20\left[{ }^{\circ} \mathrm{C}\right]$ \\
Relative humidity $(\%)$ & $101,325[\mathrm{~Pa}]$ \\
Materials characteristics & & $40[\%]$ \\
Seat (Cover) & & \\
& Specific heat & $11.65[\mathrm{~kJ} / \mathrm{kg} \mathrm{K}]$ \\
& Conductivity & $0.1610\left[\mathrm{~W} / \mathrm{m} \mathrm{K}^{3}\right]$ \\
& Density & $239.00\left[\mathrm{~kg} / \mathrm{m}^{3}\right]$ \\
Seat (polyurethane) & Thickness & $4.00 \bullet 10^{-3}[\mathrm{~m}]$ \\
& Specific heat & $1.50[\mathrm{~kJ} / \mathrm{kg} \mathrm{K}]$ \\
& Conductivity & $0.0280[\mathrm{~W} / \mathrm{m} \mathrm{K}]$ \\
Walls & Density & $76.00\left[\mathrm{~kg} / \mathrm{m}^{3}\right]$ \\
& Thickness & $0.0240[\mathrm{~m}]$ \\
& Specific heat & $1.46[\mathrm{~kJ} / \mathrm{kg} \mathrm{K}]$ \\
& Conductivity & $0.59[\mathrm{~W} / \mathrm{m} \mathrm{K}]$ \\
& Density & $1.857 \bullet 10^{3}\left[\mathrm{~kg} / \mathrm{m}^{3}\right]$ \\
& Thickness & $4.00 \bullet 10^{-3}[\mathrm{~m}]$ \\
& Specific heat & $1.20[\mathrm{~kJ} / \mathrm{kg} \mathrm{K}]$ \\
& Conductivity & $0.2400[\mathrm{~W} / \mathrm{m} \mathrm{K}]$ \\
& Density & $1.200 \bullet 10^{3}\left[\mathrm{~kg} / \mathrm{m}^{3}\right]$ \\
& Thickness & $2.00 \bullet 10^{-3}[\mathrm{~m}]$ \\
\hline
\end{tabular}




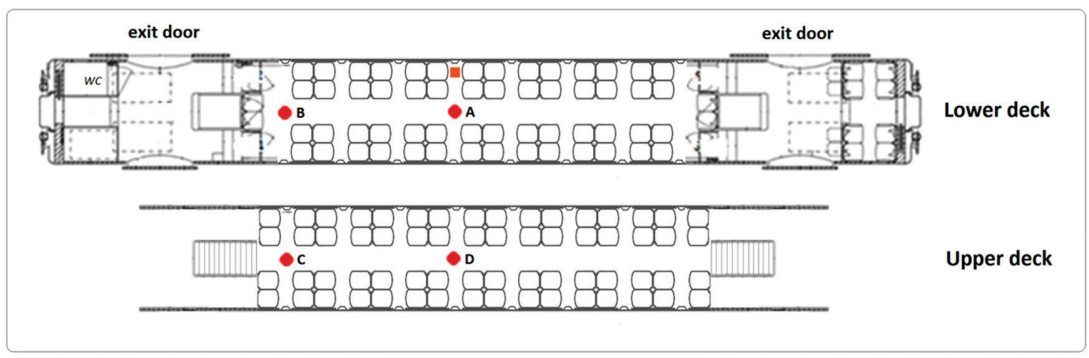

Figure 1: Layout of the rail car, with the location of the burner (orange) and of the control points (red).

compartments and some of these devices were located to detect the temperature at different height at the same point. Additional six more probes for the measurement of visibility were positioned at different points of the carriage. Only the most significant measurement is reported in this manuscript (as reported in Fig. 1). The signals of all sensors were transmitted to a computer located in another car and elaborated through a software CPI win ESF FDS, 2011 (ESF) BM systems [17]. In addition, at the control points B it was carried out the monitoring of the air quality, through the analysis of particulate matter (PM), oxygen, carbon monoxide, carbon dioxide and TOC. Samples of particulate matter were also collected in the same point for the analysis by an external laboratory of $\operatorname{TCDD}_{\mathrm{eq}}$ (dioxins and furanes) and heavy metals. The characteristics of the thermocouples, visibility sensor, multi-parameter gas analyzer $\left(\mathrm{O}_{2}, \mathrm{CO}, \mathrm{CO}_{2}\right.$ and TOC), and PM analyzer are reported below:

- Thermocouples: sensor type $\mathrm{K}(\mathrm{NiCr}-\mathrm{Ni})$, Testo 925 , accuracy \pm 0.5 , range $-50^{\circ} \mathrm{C}-1000^{\circ} \mathrm{C}$

- Visibility sensors: PSW sensor, infrared measuring system, according to WMO regulations reference table 4680 and 9328 ICAO standard. Average accuracy $\pm 10 \%$.

- Gas analyzer: non-Dispersive Infra-Red (ND-IR) analyzer, type MIR 9000 using Gas Filter Correlation technique (GFC); accuracy $\pm 2 \%$ of full scale for all parameter

- PM analyzer: electrodynamic sensor type DT 990 to detect the electrostatic charge of particulate; accuracy $\pm 1 \%$ of full scale.

The model simulation was made by means of the software CPI win FSE FDS 2011 of BM Sistems. The fundamental equations of reference of the simulating model are indicated below:

I. The mass conservation (Lagrangian Formula):

$$
\frac{\partial \rho}{\partial t}+\vec{\nabla} \cdot \rho u=0
$$

II. Energy conservation

$$
\frac{\partial}{\partial t}(\rho h)+\vec{\nabla} \cdot \rho h u=\frac{D p}{D t}+q " \cdot \dot{\vec{\nabla}} q+\varphi
$$

III. Momentum conservation

$$
\frac{\partial}{\partial t}(\rho u)+\vec{\nabla} \cdot \rho u u+\vec{\nabla} p=p f+\vec{\nabla} \cdot \tau i j
$$


IV. Equation of state of gas

$$
p=\frac{\rho R T}{M}
$$

More information in Ref. [17]. The boundary conditions were: mesh dimension 10x10x10 $\mathrm{cm}^{3}$; environmental initial temperature $20^{\circ} \mathrm{C}$; environmental pressure $101.325 \mathrm{~Pa}$; relative humidity $40 \%$.

\section{RESULTS AND DISCUSSIONS}

Figures 2 and 3 show the temperature trend at the four control points, along the fire experimentation period of $900 \mathrm{~s}$. The fire was suppressed $600 \mathrm{~s}$ after ignition. About $90 \%$ of the combustible material resulted burnt. Each figure reports the comparison between the curve obtained through modeling (red) and the curve resulting from thermocouple measurement (blue).

The horizontal axis shows the time in seconds and the ordinate axis the temperature in degrees Celsius. The purple line represents the instant of time ( 270 seconds) in which the 4 exit doors were opened; the green vertical line represents the time at which the fire was extinguished. In the lower deck the temperature (detected in points A and $\mathrm{B}$ ) increases rapidly to $100^{\circ} \mathrm{C}-120^{\circ} \mathrm{C}$ and maintains these values for about $330 \mathrm{~s}$, well after the exit door opening. The temperature begin dropping only immediately after the cease of fire. In the upper deck the temperature (detected in points $\mathrm{C}$ and $\mathrm{D}$ ) shows a similar trend, but the highest detected values are in the range $60^{\circ} \mathrm{C}-70^{\circ} \mathrm{C}$, which is appreciably lower than in the lower deck. Considering that the evacuation time of the rail car on fire was calculated in $280 \mathrm{~s}$, via a simulation
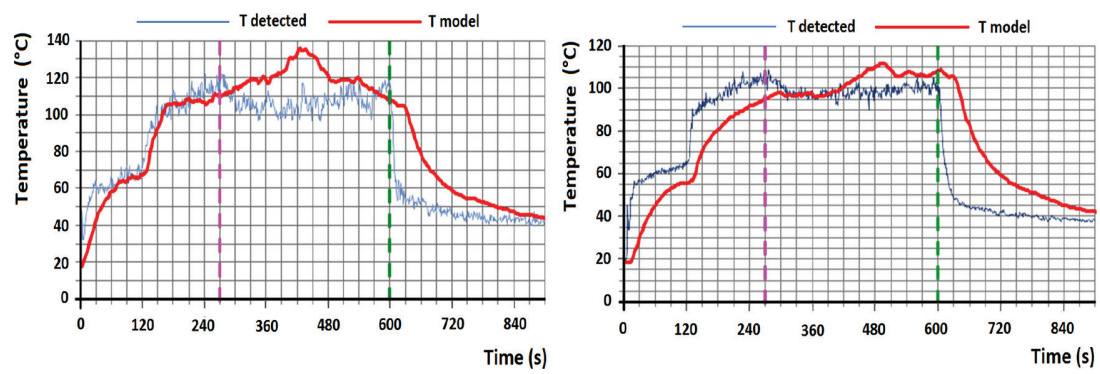

Figure 2: Temperature trend at point A and B (blue-detected; red-model).
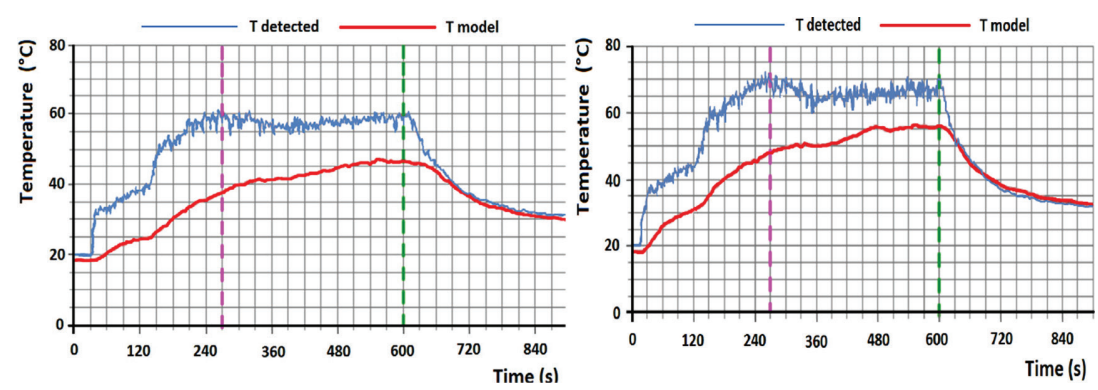

Figure 3: Temperature trend at point C and D (blue-detected; red-model). 
model (not illustrated in this article for reasons of space), throughout this period of time the exposition of passengers to the above mentioned temperature (mainly that reached in the lower deck) may determines some health risk. In general, people can survive in dry air temperatures well over $120^{\circ} \mathrm{C}$ in the short term, but with humid air the body resistance is much lower. The effects on the human health strongly depends on the sanitary condition of the people, that to say on the ability of the human organism to tolerate the heat stress. Adverse health effects of the heat stress include heat stroke, heat exhaustion, heat syncope, heat cramps, heat rashes, or even death [18]. Heat can also increase risk of injuries, as it may result in sweaty palms, fogged-up safety glasses, dizziness, and may reduce brain function responsible for reasoning ability, creating additional hazards [18]. Other heat injuries, such as burns, may occur as a result of contact with hot surfaces or fire [18].

Figures 2 and 3 prove a good correspondence of the model with the trend of the measured temperatures in the lower deck. The standard deviation between the two curves is in fact of $6.5^{\circ} \mathrm{C}$ (point $\mathrm{A}$ ) and $9.3^{\circ} \mathrm{C}$ (point $\mathrm{B}$ ). Instead, there is a greater standard deviation in the upper deck, of $15^{\circ} \mathrm{C}$ in point $\mathrm{C}$ and $16.5^{\circ} \mathrm{C}$ in point $\mathrm{D}$. The deviation is particularly pronounced for the entire period that precedes the opening of the exit doors, while later gradually tends to decrease until reaching the alignment of the two curves after the fire suppression. It is believed that the reason for the strong initial deviation can be determined by the high heat transmission from the lower deck to the upper deck through the separating insole. This phenomenon is not contemplated in the model, thus implying an underestimation of temperatures calculated with respect to the actual temperature. A confirmation of this thesis is given by the realignment of the curves in the period that follows the fire suppression. The separation pad between the two levels has a purely structural and non-insulating function. Thickness is also minimal.

It deserves highlight that previous experiments with full-scale rail cars and with physical models have shown the achievement of significantly higher temperatures $[19,20]$. This is in part determined by the use of different materials and in part by the greater total volume of bilevel rail car experienced in this specific research.

Figure 4 shows the trend of the visibility measured during the time evolution (abscissa) at the four control points in the rail car, A, B, C and D. The visibility in all the control points deteriorates very rapidly until it reaches a minimum value just before the opening of the doors. The absolute minimum of about $6 \mathrm{~m}$ is reached at point $\mathrm{A}$, while slightly higher values, between $9 \mathrm{~m}$ and $11 \mathrm{~m}$, correspond to points B, C and D. The opening of the exit doors determines the improvement of the visibility in all the control points. The point $\mathrm{B}$ (the nearest to the exit doors) is the first to regain the normal visibility, immediately followed by the point

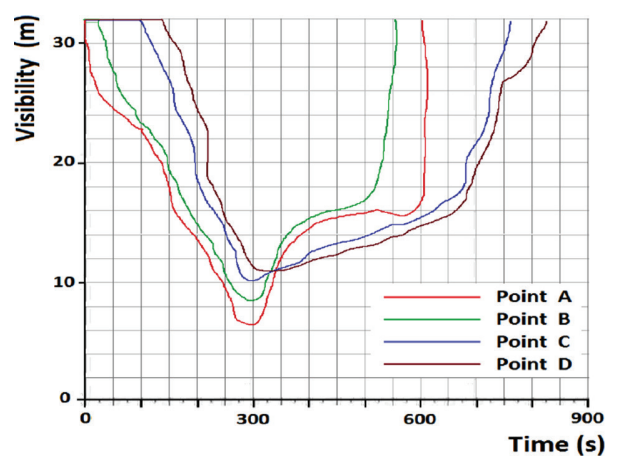

Figure 4: Visibility detected at the four control points A, B, C and D in the carriage. 
A. Longer times are instead necessary for the points $C$ and $D$ on the upper deck. The figure clearly shows the relevance of the fire suppression on the restoration of normal visibility into the two decks. The trend of the visibility curves, as a whole corresponds to the following sequence of events (visually verified during experimentation) relating to the formation and distribution of the smoke in the carriage:

1. fire ignition and smoke formation;

2. propagation of smoke in the lower deck of the carriage;

3. propagation of smoke in the whole carriage, till the opening of the exit doors which occurs 270 seconds after the start of the fire;

4. stratification of the flue gas after the exit door opening;

5. progressive reduction in the thickness of the smoke up to fire off.

Figure 5 shows the trend of the air quality in point B during the experimentation.

The rate of heat released follows the temperature over time, but in the specific case it has not been introduced in the evaluation, because the actual field measurements have enabled the temperatures to be directly detected by thermocouples positioned in the wagon. The fire causes a rapid and considerable reduction of oxygen (red curve), up to a minimum value of $9.6 \%$ by volume. After the opening of the exit doors the oxygen content in the air grows back gradually up to the normal value of about $22 \%$. The growth back is particularly pronounced in the period immediately following the fire suppression. The reduction of the oxygen coincides with the growth of the carbon dioxide (blue line) and carbon monoxide (green line), the latter as a consequence of the very poor efficiency of the combustion. The concentrations of $\mathrm{CO}_{2}$ and $\mathrm{CO}$ decrease after the opening of the exit doors, and even more after the fire suppression. The smoke produced by the combustion contains a significant concentration of PM and TOC, up to maximum values of respectively $2200 \mathrm{mg} / \mathrm{Nm}$ and $800 \mathrm{mg} / \mathrm{Nm}$. As for carbon monoxide, also the TOC is representative of a highly incomplete combustion. The opening of the doors and the fire suppression favor the evacuation of smoke and the return to the normality values of these two parameters.

The minimum value of $15 \%$ oxygen was not set to keep combustion.

The analysis of PM showed the presence of the following contaminants: $0.001 \mathrm{mg} / \mathrm{kg}$ TCDDeq, 12 mg/kg Cr III, 120 mg/kg Zn, 95 mg/kg Pb, 18 mg/kg Ni, 3.1 mg/kg Cd.

The natural transport of combustion fumes outside the carriage, inevitably leads to environmental pollution. Figure 6 shows the load of the pollutants transported by smoke to the atmosphere.

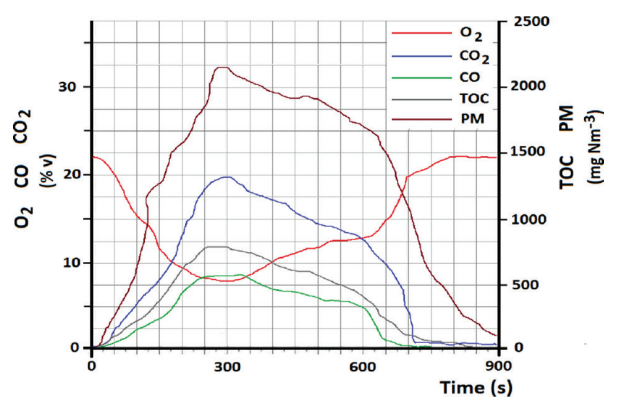

Figure 5: Trend of air quality in the control point B. 


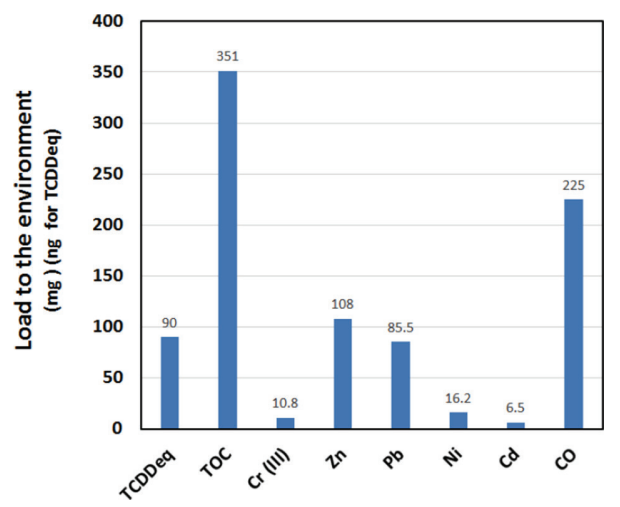

Figure 6: Load of toxic chemicals emitted to the environment (all chemicals in mg except TCDDeq in ng).

It is very hard to determine the risk of exposition to these contaminants because many factors will determine whether a person can be harmed, or not. These factors include the dose, the duration, and how a person come in contact with it. It should also be considered the combined action of the different chemicals as well as the age, sex, diet, family traits, lifestyle, pregnancy status, and state of health. However, in some case the lack of oxygen could determine a mild headache, nausea and vomiting, but these symptoms should go away on their own within a short time. Instead the short term exposition to carbon monoxide could be more harmful to passenger with heart or lung disease; furthermore, breathing carbon monoxide during pregnancy can harm the unborn child [21].

The environmental risk in principle could be considered very modest since the load of pollutants emitted is quite limited. With regard to persistent contaminants with high toxicological characteristics (TCDD $_{\text {eq }}$ and heavy metals) it should be considered that the concentrations found in the PM are particularly low (of a smaller order of magnitude than found in flying ash of municipal waste incinerators [22-24]). The carbon monoxide is a still lesser danger. In fact, EPA established an environmental limit of $10 \mathrm{mg} / \mathrm{Nm}^{3}$ of $\mathrm{CO}$ in air averaged over 8 hours. This limit is not to be exceeded more than once per year [21]. Rapid dispersion of smoke in the atmosphere should very easily ensure compliance with this limit. Furthermore, the $\mathrm{CO}$ released in the environment undergoes the spontaneous oxidation to carbon dioxide within two months. Therefore, the incidence of some very dangerous contaminants, such as dioxins, could be considered marginal compared to carbon monoxide. These considerations should, however, be contextualized according to the pre-existing contamination level at the event. In the absence of specific data it is impossible to conduct a more thorough evaluation of the toxicological aspects.

\section{CONCLUSIONS}

The main aspects emerged from the experience are:

1. The fire in rail cars strongly depends on the quality of combustible materials used for its construction. The indoor temperature can grow up to critical values for the human health. In this specific research the maximum temperature of $120^{\circ} \mathrm{C}$ (at head height, $1.7 \mathrm{~m}$ above the floor) was reached in the lower deck of the experimented bilevel rail car. 
2. Temperature in the range of $100^{\circ} \mathrm{C}-120^{\circ} \mathrm{C}$ were maintained for about $300 \mathrm{~s}$, so that to determine some health risk for passengers, mainly for those whose organism does not tolerate the heat stress. In the upper deck the maximum detected temperature was lower $\left(70^{\circ} \mathrm{C}\right)$, thus reducing the risk of injuries.

3. However, it is worth to mention that previous experimentations demonstrated the possibility to reach temperature greater than $400^{\circ} \mathrm{C}$.

4. The simulation of fire spreading in the rail car with a mathematical model (software $C P I$ win FSE FDS 2011 of BM Sistems) allowed a good validation of the same model. In fact, in the lower deck the maximum deviation from the detected temperature with thermocouples was $9.5^{\circ} \mathrm{C}$. Thus, the numerical model proved to be an effective simulation tool of the dynamics of a fire in a railway carriage.

5. Instead, the model underestimates the trend of air temperature in the upper deck (maximum deviation of $16.5^{\circ} \mathrm{C}$ ), likely because of the strong heat transmission from the lower deck to the upper deck through the separating insole. This phenomenon is not covered by the model, which therefore needs to be improved for specific applications in bilevel rail cars.

6. The fire causes a rapid and considerable reduction of oxygen, down to a minimum value of $9.6 \%$ by volume and the increase of the concentration of particulate matter and total organic carbon, up to maximum values of respectively $2200 \mathrm{mg} / \mathrm{Nm}^{3}$ and $800 \mathrm{mg} / \mathrm{Nm}^{3}$. The analysis of the collected particulate matter evidenced a very low presence of toxic

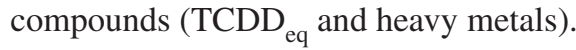

The risk of exposition of passengers to these conditions strongly depends from their health state. In some cases, the lack of oxygen could determine a mild headache, nausea and vomiting, but these symptoms should go away on their own within a short time. Instead the short term exposition to carbon monoxide could be more harmful to passenger with heart or lung disease; furthermore, breathing carbon monoxide during pregnancy can harm the unborn child.

The environmental risk can be considered very modest since the load of pollutants emitted is quite limited and the natural dispersion of smoke in the atmosphere will lower the impact.

Overall, it is believed that the results of this research will help to improve the knowledge about the risk of fire in the passengers rail cars and particularly with respect to bilevel rail cars. Also, the modeling simulation of fire on this type of carriage and the results regarding environmental pollution represent a new and original contribution to the scientific knowledges in this specific field. However, the modeling simulation produced very good results for the lower deck, whereas has demonstrated some limitations for the upper deck.

\section{REFERENCES}

[1] Van Den Bosh, C.J.H., RAPM Weterings. Methods for the Calculation of Physical Effects, 3rd edn., The Netherlands Organization of Applied Scientific Research, The Hague, The Netherlands, 2005.

[2] La Repubblica (on line news dated June 30th 2009), available at www.repubblica.it

[3] Rai news24 (on line news dated February 18th 2004), available at www.rainews.it

[4] Liu, X., Saat, M.R. \& Barkan, C.P.L., Probability analysis of multiple-tank-car release incidents in railway hazardous materials transportation. Journal of Hazardous Materials, 276, pp. 442-451, 2014.

https://doi.org/10.1016/j.jhazmat.2014.05.029 
[5] Chilton, S., Covey, J., Hopkins, L., Jones-Lee, M., Loomes, G., Pidgeon, N. \& Spencer, A., Perceptions of risk and preference-based values of safety. Journal of Risk and Uncertainty, 25, pp. 211-232, 2012. https://doi.org/10.1023/A:1020962104810

[6] Kales, S.N., Soteriades, E.S., Christophi, C.A. \& Christiani, D.C., Emergency duties and deaths from heart disease among firefighters in the United States. The New England Journal of Medicine, 356, pp. 1207-1215, 2007. https://doi.org/10.1056/NEJMoa060357

[7] Di Mauro, C., Bouchon, S. \& Torretta, V., Industrial risk in the Lombardy Region (Italy): what people perceive and what are the gaps to improve the risk communication and the participatory processes. Chemical Engineering Transactions, 26, pp. 297-302, 2012.

[8] European Community. Tranfeu, available at www.transfeu.eu

[9] Torretta, V., Transportation of dangerous substances: a decisional support system for risk analysis. Proceedings of CBEE 2009 International Conference on Chemical, Biological \& Environmental Engineering, Singapore, pp. 310-314, 2009. https://doi.org/10.1142/9789814295048_0063

[10] Paltrinieri, N., Landucci, G., Molag, M., Bonvicini, S., Spadoni, G. \& Cozzani, V., Risk reduction in road and rail LPG transportation by passive fire protection. Journal of Hazardous Materials, 167, pp. 332-344, 2009. https://doi.org/10.1016/j.jhazmat.2008.12.122

[11] Torretta, V., Raboni, M., Copelli, S. \& Urbini, G., Application of a decision support system to the transport of hazardous materials. Journal of Environmental Engineering and Management, 12(10), pp. 2031-2039, 2013.

[12] Forsberg, R. \& Björnstig, U., One hundred years of railway disasters and recent trends. Prehospital and Disaster Medicine, 26, pp. 367-373, 2011. https://doi.org/10.1017/S1049023X1100639X

[13] Markos, S.H. \& Volpe, J.A., Comparison of the US and European approaches to passenger train fire safety. Proceedings of the 2nd International Fire in Vehicles (FIVE), Chicago, USA, 2012.

[14] Zhu, J., Li, X.J. \& Mie, C.F., Combustion performance of flame-ignited high-speed train seats via full-scale tests. Case Studies in Fire Safety, 4, pp. 39-48, 2015. https://doi.org/10.1016/j.csfs.2015.05.002

[15] Directive 2006/90/EC of 3 November 2006 adapting for the seventh time to technical progress Council Directive 96/49/EC on the approximation of the laws of the Member States with regard to the transport of dangerous goods by rail. Bruxelles, Belgium, 2006.

[16] Gheorhe, A.V., Birchmeier, J., Vamanu, D., Papazoglou, I. \& Kröger, W., Comprehensive risk assessment for rail transportation of dangerous goods: a validated platform for decision support. Reliability Engineering \& System Safety, 88, pp. 247-272, 2005. https://doi.org/10.1016/j.ress.2004.07.017

[17] BM Systems, Antifire products. Online: www.bmsistemi.com/software-antincendio.asp

[18] NIOSH-National Institute for Occupational Safety and Health. Criteria for a recommended standard: occupational exposure to heat and hot environments. DHHS (NIOSH) Publication No. 2016-106, Cincinnati, USA. 2016.

[19] Contini, S., Copelli, S., Raboni, M., Torretta, V., Sala Cattaneo, C. \& Rota, R., IEC 6158: effect of test policy on the probability of failure on demand of safety instrumented systems. Chemical Engineering Transactions, 33, pp. 487-492, 2013. 
[20] Ingason, H., Model scale railcar fire tests. Brand for sk-project 404-011, SP Fire Technology, 48, 2005.

[21] U.S. DEPARTMENT OF HEALTH AND HUMAN SERVICES, Public Health Service Agency for Toxic Substances and Disease Registry. Toxicological Profile for Carbon Monoxide, Atlanta, USA, 2012.

[22] Valerio, F., Review on environmental impact of solid wastes produced by municipal urban waste incinerators. E\& P-Epidemiologia \& Prevenzione, 32(4-5), pp. 244-253, 2008.

[23] Rada, E.C., Ragazzi, M., Ionescu, G., Merler, G., Moedinger, F., Raboni, M. \& Torretta, V., Municipal solid waste treatment by integrated solutions. Energy Procedia, 50, pp. 1037 1044, 2014.

https://doi.org/10.1016/j.egypro.2014.06.123

[24] Torretta, V., Ionescu, G., Raboni, M. \& Merler, G., Mass and energy balance of an integrated solution for municipal solid waste treatment. WIT Transactions on Ecology and the Environment, 180, pp. 151-161, 2014.

https://doi.org/10.1016/j.egypro.2014.06.123 